Review

International Journal of Medical Sciences

ISSN 1449-1907 www.medsci.org 2007 4(2):110-114

(c) Ivyspring International Publisher. All rights reserved

\title{
Childhood Febrile Seizures: Overview and Implications
}

\author{
Tonia Jones, Steven J. Jacobsen \\ Research and Evaluation, Kaiser Permanente Southern California, Pasadena, CA 91101, USA
}

Correspondence to: Tonia Jones, RN, FNP, Ph.D, Research and Evaluation, Kaiser Permanente Southern California, Pasadena, CA 91101, Phone: (626) 564-3483, Fax: (626) 564-3430, Email: tonia.l.jones@kp.org

Received: 2007.03.14; Accepted: 2007.04.04; Published: 2007.04.07

This article provides an overview of the latest knowledge and understanding of childhood febrile seizures. This review also discusses childhood febrile seizure occurrence, health services utilization and treatment costs. Parental reactions associated with its occurrence and how healthcare providers can assist parents with dealing effectively with this potentially frightening and anxiety-producing event are also discussed.

Key words: childhood febrile seizure, parental reaction, anxiety, health services utilization, parental education

\section{Introduction}

Although the occurrence of febrile seizures in childhood is quite common, they can be extremely frightening, emotionally traumatic and anxiety provoking when witnessed by parents. During the seizure, the parent may perceive that their child is dying $[1 ; 2]$, but fortunately the vast majority of febrile seizures are benign. Rarely have febrile seizures caused brain damage [3] and with the exception of developing countries, there are no documented cases of febrile seizure-related deaths on record [4]. There have been numerous reviews and updates which have explored the natural history, treatment and subsequent outcomes of febrile seizures [5]. In addition, several articles have addressed the immediate parental reaction to this occurrence $[1 ; 6-11]$, and one has addressed parental reaction over time [10]. In this article, we provide a brief overview of childhood febrile seizures and explore the potential parental reactions to febrile seizures from physiological, emotional, and behavioral perspectives. We also include a review of health services utilization and the treatment costs of children experiencing febrile seizures, an aspect that has not been considered to any depth in relation to childhood febrile seizures.

\section{Febrile Seizures Defined}

Febrile seizures have defined by The International League Against Epilepsy (ILAE) as "a seizure occurring in childhood after one month of age, associated with a febrile illness not caused by an infection of the central nervous system, without previous neonatal seizures or a previous unprovoked seizure, and not meeting criteria for other acute symptomatic seizures [12]. Febrile seizures are classified as either simple or complex. Simple febrile seizures consist of a brief (lasting less than 10 minutes) tonic-clonic convulsion which occurs only once within a 24-hour period. There are no focal features and it resolves spontaneously [13].
Conversely, complex febrile seizures are prolonged (greater than 10-15 minutes), focal, or multiple (recurrent within the same febrile illness over a 24-hour period). While the majority of febrile seizures are simple $(70-75 \%)$ [14], $9-35 \%$ of febrile seizures are complex [15].

\section{Natural History}

Approximately one- half million febrile seizure events occur per year in the US [16]. Most febrile seizures occur between 6 months and 36 months of age, peaking at 18 months [15]. The incidence of febrile seizures is between $2-5 \%$ [17], with at least 3\% to $4 \%$ of all children in North America experiencing at least one febrile seizure before the age of 5 years [18]. The occurrence of a child's first (initial) febrile seizures has been associated with: first or second-degree relative with history of febrile and afebrile seizures [19], day care attendance [20;21], developmental delay [19;21], Influenza A viral infection [18;22], Human herpesvirus-6 infection [23;24], Metapneumovirus [25], and iron deficiency anemia [26]. Other exogenous circumstances that have been identified as predicting an increased risk of initial febrile seizures include difficult birth, neonatal asphyxia, and coiling of the umbilical cord [27]. Children with febrile seizures and the exogenous conditions previously listed are likely to have affected family members, and have a risk of recurrence of seizures on $\geq 5$ occasions [27].

The risk of initial febrile seizures has also been studied after receipt of pediatric vaccinations such as diphtheria-tetanus-whole cell pertussis (DTP) [28;29] and Measles, Mumps and Rubella (MMR) [30;31]. Studies by Barlow and associates (2001) and Walker and colleagues (1988) found a 4-fold increase in the risk of febrile seizures within 1-3 days of receipt of DTP vaccination. With regard to MMR vaccination, the risk of febrile seizures increases by 1.5 and 3.0 fold, with the peak occurring 1-2 weeks after vaccination [30;32]; an additional 25-34 febrile seizures have been 
estimated to occur per 100,000 doses of MMR administered [30].

Febrile seizures frequently recur. Although febrile seizure usually occur as single, isolated incidents, the reoccurrence rate is 30\% overall [33], and increases to $50 \%$ if the initial febrile seizure occurs in a child under one year of age [34]. Of those who experience a second febrile seizure, the risk of recurrence increases 2 -fold [35;36]. Predictors of recurrent febrile seizures include: a history of focal, prolonged, and multiple seizures [37;38], Influenza A viral infection [39], family history of febrile seizures [36], onset of febrile seizure $<12$ months of age [40], temperature $<40^{\circ} \mathrm{C}\left(<104^{\circ} \mathrm{F}\right)$ at time of seizure [41], and a history of complex, initial febrile seizures [42]. A low proportion (2-4\%) of children who experience at least one febrile seizure event [4;43], go on to develop recurrent afebrile seizures (epilepsy) [16;44].

\section{Febrile Seizure Evaluation and Manage- ment}

While febrile illnesses in infants and children account for $10-20 \%$ of all pediatric, emergency room visits [45], up to one percent of these visits involve pediatric seizure patients [46;47]. Eighty percent of those pediatric seizure patients are diagnosed with febrile seizures, and $20 \%$ are diagnosed with afebrile seizures [48-50]. Seizures of any type are usually a manifestation of a number of underlying pathologic conditions to differentiate between them, careful history taking, physical examination, and laboratory work-up are usually required. EEG's and neuroimaging studies should be performed as dictated by clinical suspicion, as routine ordering of neuroimaging studies and EEG's have been found to have limited value. Abnormalities on EEG do not predict the occurrence of future seizures [51] or the subsequent development of epilepsy [17]. Practice guidelines have recommended that lumbar punctures be strongly considered in children experiencing their first simple febrile seizure, particularly if $<18$ months of age $[15 ; 20 ; 52 ; 53]$ In the case of first simple febrile seizure, prophylactic antipyretic or anticonvulsant therapies are not recommended to reduce the recurrence rate [54;55]. As to the short-term treatment of ongoing febrile seizures, anticonvulsants such as Phenobarbital and Diazepam have been found to reduce the reoccurrence of febrile seizures, but not subsequent development of epilepsy [56].

\section{Health Services Utilization and Treatment Costs of Children with Febrile Seizures}

There are few data available regarding health services utilization and treatment costs of children experiencing febrile seizure events. The majority of studies evaluating health services utilization and treatment costs have been in children diagnosed with epilepsy [57-62]. The costs to initially evaluate and treat febrile seizures depend on the clinical work-up indicated by clinical suspicion.

In 2003, Freeman detailed the cost of evaluating an initial afebrile seizure in the emergency room (US \$3057) and concluded that less testing is needed in the ER following this occurrence [63]. Two studies have indicated that children with febrile seizures do not consume excess health care resources. In a matched case-control study, 75 children experiencing their first febrile seizure were age-matched with 150 febrile and 150 afebrile controls. It was concluded that children with febrile seizures had nearly identical rates of subsequent hospitalization when compared with age-matched controls [18]. A secondary analysis of this same data set was undertaken, and it was found that children with a known family history of febrile seizures at the time of study entry had $24 \%$ fewer physician visits [64]. In contrast, children experiencing their first febrile seizure had $45 \%$ more physician visits when they knew of a relative with afebrile seizures than those with negative family histories. Thus, it appears that knowledge of a family history of febrile seizures is correlated with reduced office visits.

\section{Parental Reaction and Response to Febrile Seizures in Children}

Parental reaction and response to febrile seizure occurrence in children can comprise physical, psychological, and behavioral manifestations. Common physical symptoms experienced by parents following their child's febrile seizure include dyspepsia [65], anorexia [1], and sleep disruption [1;8;9;65]. Psychological reactions experienced by parents include fear of reoccurrence [8], fear of subsequent development of epilepsy [1], apprehension, and excessive anxiety and worry about low-grade fevers [66].

The occurrence of febrile seizures can potentially disrupt the familial quality of life and the parents may experience anxiety and fear whenever a child develops a fever. These parents may also perceive that somehow the child is now "vulnerable" or unusually susceptible to medical or developmental problems [18]. The full term to describe this perception is referred to as the "vulnerable child syndrome", which includes a compilation of behaviors that are thought to develop as a result of this excessive parental anxiety $[67 ; 68]$. These parents experience increased anxiety and fear [68] whenever a child develops a fever [8;9]. As a result, this heightened parental fear of fever and febrile seizures can have series negative consequences on daily family life $[1 ; 4]$, parental behavior $[4 ; 69]$ and parent-child interactions [68;70;71]. As a consequence of this perceived "vulnerability", it would seem intuitive that the caregiver would seek medical attention for their child more frequently, as this was repeatedly found in previous parent-perceived child vulnerability studies involving general pediatrics and premature infants [70;72-74]. But to the contrary, as noted earlier in two studies [18;64], children experiencing febrile seizures did not utilize a higher rate of resources compared with age-matched controls.

\section{Implications}

The occurrence of childhood febrile seizures are 
common; thus parents and caregivers should be provided information about them. Instructions and parental education should be specific, written in lay terms, tailored to their language and culture and address the following (See Table 1):

Table 1: Febrile Seizure Information and Education

\section{Clinical Information}

What is a febrile seizure?

The link between fever and febrile seizures (FS) in children.

What may happen to the child during the febrile seizure?

What measure(s) should be taken or avoided during the febrile seizure event.

What does not happen to the child's brain during a febrile seizure?

The likelihood of reoccurrence.

When to consult a healthcare provider, when to call 911 and when take the child directly to an emergency room (ER).

What may occur during the healthcare provider's evaluation and/or testing of the child

What are the possible sequelae of febrile seizures?

What treatments may be prescribed (i.e anticonvulsants), when they are indicated, and possible adverse effects.

\section{Summary}

Childhood febrile seizures, although primarily benign, can be frightening and anxiety-provoking events for parents and caregivers. It is important that health care providers understand potential parental misconceptions, anxieties and fears about fever and febrile seizures so that they may allay those fears effectively. The healthcare provider also needs to assess parental reactions to the occurrence of febrile seizure and to determine the coping patterns utilized as well as to detect any disruptions in parent-child interactions. Additional studies are needed to evaluate the costs of treatment for initial febrile seizures as well as health services utilization.

\section{Conflict of interest}

The authors have declared that no conflict of interest exists.

\section{References}

1. Parmar RC, Sahu DR, Bavdekar SB. Knowledge, attitude and

\section{Clinical Education}

Febrile seizures are convulsions brought on by a fever in infants or small children. Most febrile sei-

Febrile Seizures occur in 3\% -5\% of otherwise healthy children 6-60 months of age. It is debated by to more than 15 minutes.

the rise in temperature or the height of the temperature which triggers the seizure. The seizure is often the first sign of a fever.

During a febrile seizure, a child may lose consciousness or responsiveness, shake and move limbs on a the body. The child becomes rigid or has twitches in only a portion of the body, such as

Do stay calm. Focus your attention on bringing the fever down. Insert rectal acetaminophen (Tylenol) (if available). Apply cool washcloths to the forehead and neck. Sponge the rest of the body with lukewarm (not cold) water. Loosen any restrictive clothing.

Don't try to hold or restrain the child or stop the seizure movements. Don't try to force anything into prevent him from biting his tongue as this increases the risk of injury. Move the child only if in a dangerous situation. Remove any objects that may injure him.

A third of children will have another febrile seizure with a subsequent fever. Of those who do, about $1 / 2$ will have a $3^{\text {rd }}$ seizure. If there is a family history, if the first seizure happened before 12 months of , or if the seizure happened with a fever below 102, a child is more likely to have $>1$ febrile seizures.

1. Children should consult a healthcare provider as soon as possible after the first febrile seizure. 2. Call 911 if the seizure lasts more than a few minutes.

3. Contact a healthcare provider or go to the ER if any other symptoms occur before or after the seig, rash, tremors, abnormal movements, problems with coordination, drowsiness, agitation, confusion, sedation, etc.

Blood and urine tests may be examined to detect infections. Typically, a full seizure workup includInjuries caused by falling or bumping into objects. Biting oneself

Pneumonia secondary to fluid aspiration. Injury from prolonged or complicated seizures.

Medication side effects related to the treatment and prevention of seizures (if prescribed). if a serious infection, such as meningitis caused the fever.

Seizures unrelated to fever (afebrile seizures)
Parental perception of increased child vulnerability to medical or developmental problems.

The list of epilepsy medications used depends on clinical plan devised practices of parents of children with febrile convulsion. J.Postgrad.Med. 2001; 47: 19-23.

2. Deng CT, Zulkifli HI, Azizi BH. Parental reactions to febrile seizures in Malaysian children. Med.J.Malaysia 1996; 51: 462-8.

3. Verity CM. Do seizures damage the brain? The epidemiological evidence. Arch Dis Child 1998; 78: 78-84.

4. Gordon KE, Dooley JM, Camfield PR, Camfield CS, MacSween J. Treatment of febrile seizures: the influence of treatment efficacy and side-effect profile on value to parents. Pediatrics 2001; 108: 1080-8.

5. Varma RR. Febrile seizures. Indian J.Pediatr. 2002; 69: 697-700.

6. Schmitt BD. Fever phobia: misconceptions of parents about fevers. Am.J.Dis.Child 1980; 134: 176-81.

7. Shuper A, Gabbay U, Mimouni M. Parental anxiety in febrile convulsions. Isr.J.Med.Sci. 1996; 32: 1282-5.

8. van Stuijvenberg M, de Vos S, Tjiang GC, Steyerberg EW, Derksen-Lubsen G, Moll HA. Parents' fear regarding fever and febrile seizures. Acta Paediatr. 1999; 88: 618-22.

9. Flury T, Aebi C, Donati F. Febrile seizures and parental anxiety: does information help? Swiss.Med.Wkly. 2001; 131: 556-60.

10. Huang MC, Liu CC, Chi YC, Huang CC, Cain K. Parental concerns for the child with febrile convulsion: long-term effects of educational interventions. Acta Neurol.Scand. 2001; 103: 288-93.

11. Huang MC, Liu CC, Huang CC, Thomas K. Parental responses 
to first and recurrent febrile convulsions. Acta Neurol.Scand. 2002; 105: 293-9.

12. ILAE. Guidelines for epidemiologic studies on epilepsy. Epilepsia 1993; 34: 592-596.

13. Baumann RJ. Technical report: treatment of the child with simple febrile seizures. Pediatrics 1999; 103: e86.

14. Shinnar S and O'Dell C. Profiles in Seizure Management. In: Leppik IE ed. Managing Febrile Seizures in Young Children and Epilepsy in the Elderly. Princeton Media Associates. 2003: 3-15.

15. Waruiru C, Appleton R. Febrile seizures: an update. Arch.Dis.Child 2004; 89: 751-6.

16. Applegate MS, Lo W. Febrile seizures: current concepts concerning prognosis and clinical management. J.Fam.Pract. 1989; 29: 422-8.

17. Joshi C, Wawrykow T, Patrick J, Prasad A. Do clinical variables predict an abnormal EEG in patients with complex febrile seizures? Seizure. 2005; 14: 429-34.

18. Gordon KE, Camfield PR, Camfield CS, Dooley JM, Bethune P. Children with febrile seizures do not consume excess health care resources. Arch.Pediatr.Adolesc.Med. 2000; 154: 594-7.

19. Bethune P, Gordon K, Dooley J, Camfield C, Camfield P. Which child will have a febrile seizure? Am.J.Dis.Child 1993; 147: 35-9.

20. Shinnar S, Glauser TA. Febrile seizures. J.Child Neurol. 2002; 17 (Suppl 1): S44-S52.

21. Millar JS. Evaluation and treatment of the child with febrile seizure. Am.Fam.Physician 2006; 73: 1761-4.

22. Chiu SS, Tse CY, Lau YL, Peiris M. Influenza A infection is an important cause of febrile seizures. Pediatrics 2001; 108: E63.

23. Barone SR, Kaplan MH, Krilov LR. Human herpesvirus-6 infection in children with first febrile seizures. J.Pediatr. 1995; 127: 95-7.

24. Hall CB, Long CE, Schnabel $\mathrm{KC}$ et al. Human herpesvirus-6 infection in children. A prospective study of complications and reactivation. N Engl J Med. 1994; 331: 432-8.

25. Peiris JS, Tang WH, Chan $\mathrm{KH}$ et al. Children with respiratory disease associated with metapneumovirus in Hong Kong. Emerg.Infect.Dis. 2003; 9: 628-33.

26. Naveed $u R$, Billoo AG. Association between iron deficiency anemia and febrile seizures. J.Coll.Physicians Surg.Pak. 2005; 15: 338-40.

27. Tsuboi T, Okada S. Exogenous causes of seizures in children: a population study. Acta Neurol.Scand. 1985; 71: 107-13.

28. Walker AM, Jick H, Perera DR, Knauss TA, Thompson RS. Neurologic events following diphtheria-tetanus-pertussis immunization. Pediatrics 1988; 81: 345-9.

29. Barlow WE, Davis RL, Glasser JW et al. The risk of seizures after receipt of whole-cell pertussis or measles, mumps, and rubella vaccine. N.Engl.J.Med. 2001; 345: 656-61.

30. Davis RL, Barlow W. Placing the risk of seizures with pediatric vaccines in a clinical context. Paediatr.Drugs 2003; 5: 717-22.

31. Vestergaard M, Hviid A, Madsen KM et al. MMR vaccination and febrile seizures: evaluation of susceptible subgroups and long-term prognosis. JAMA 2004; 292: 351-7.

32. Griffin MR, Ray WA, Mortimer EA, Fenichel GM, Schaffner W. Risk of seizures after measles-mumps-rubella immunization. Pediatrics 1991; 88: 881-5.

33. Huang MC, Huang CC, Thomas K. Febrile convulsions: development and validation of a questionnaire to measure parental knowledge, attitudes, concerns and practices. J.Formos.Med.Assoc. 2006; 105: 38-48.

34. Rose W, Kirubakaran C, Scott JX. Intermittent clobazam therapy in febrile seizures. Indian J.Pediatr. 2005; 72: 31-3.

35. Nelson KB, Ellenberg JH. Prognosis in children with febrile seizures. Pediatrics 1978; 61: 720-7.

36. Offringa M, Bossuyt PM, Lubsen J et al. Risk factors for seizure recurrence in children with febrile seizures: a pooled analysis of individual patient data from five studies. J.Pediatr. 1994; 124:
574-84.

37. Berg AT, Shinnar S, Hauser WA, Leventhal JM. Predictors of recurrent febrile seizures: a metaanalytic review. J.Pediatr. 1990; 116: 329-37.

38. Peiffer A, Thompson J, Charlier $C$ et al. A locus for febrile seizures (FEB3) maps to chromosome 2q23-24. Ann.Neurol. 1999; 46: $671-8$.

39. van Zeijl JH, Mullaart RA, Borm GF, Galama JM. Recurrence of febrile seizures in the respiratory season is associated with influenza A. J.Pediatr. 2004; 145: 800-5.

40. van Stuijvenberg M, Steyerberg EW, Derksen-Lubsen G, Moll HA. Temperature, age, and recurrence of febrile seizure. Arch.Pediatr.Adolesc.Med. 1998; 152: 1170-5.

41. van Stuijvenberg M, Derksen-Lubsen G, Steyerberg EW, Habbema JD, Moll HA. Randomized, controlled trial of ibuprofen syrup administered during febrile illnesses to prevent febrile seizure recurrences. Pediatrics 1998; 102: E51.

42. al Eissa YA. Febrile seizures: rate and risk factors of recurrence. J.Child Neurol. 1995; 10: 315-9.

43. Nelson KB, Ellenberg JH. Predictors of epilepsy in children who have experienced febrile seizures. N.Engl.J.Med. 1976; 295: 1029-33.

44. Annegers JF, Hauser WA, Elveback LR, Kurland LT. The risk of epilepsy following febrile convulsions. Neurology 1979; 29: 297-303.

45. Steere M, Sharieff GQ, Stenklyft PH. Fever in children less than 36 months of age--questions and strategies for management in the emergency department. J.Emerg.Med. 2003; 25: 149-57.

46. Krumholz A, Grufferman S, Orr ST, Stern BJ. Seizures and seizure care in an emergency department. Epilepsia 1989; 30: 175-81.

47. Huff JS, Morris DL, Kothari RU, Gibbs MA. Emergency department management of patients with seizures: a multicenter study. Acad.Emerg.Med. 2001; 8: 622-8.

48. Smith RA, Martland T, Lowry MF. Children with seizures presenting to accident and emergency. J Accid.Emerg Med 1996; 13: 54-8.

49. Herrgard EA, Karvonen M, Luoma L et al. Increased number of febrile seizures in children born very preterm: relation of neonatal, febrile and epileptic seizures and neurological dysfunction to seizure outcome at 16 years of age. Seizure. 2006; 15: 590-7.

50. Zerr DM, Blume HK, Berg AT et al. Nonfebrile illness seizures: a unique seizure category? Epilepsia 2005; 46: 952-5.

51. Kuturec M, Emoto SE, Sofijanov N et al. Febrile seizures: is the EEG a useful predictor of recurrences? Clin.Pediatr.(Phila) 1997; 36: 31-6.

52. Warden CR, Zibulewsky J, Mace S, Gold C, Gausche-Hill M. Evaluation and management of febrile seizures in the out-of-hospital and emergency department settings. Ann Emerg Med 2003; 41: 215-22.

53. al Eissa YA. Lumbar puncture in the clinical evaluation of children with seizures associated with fever. Pediatr Emerg Care 1995; 11: 347-50.

54. Uhari M, Rantala H, Vainionpaa L, Kurttila R. Effect of acetaminophen and of low intermittent doses of diazepam on prevention of recurrences of febrile seizures. J.Pediatr. 1995; 126: 991-5.

55. Knudsen FU. Febrile seizures: treatment and prognosis. Epilepsia 2000; 41: 2-9.

56. Pust B. [Febrile seizures--an update]. Kinderkrankenschwester. 2004; 23: 328-31.

57. Begley CE, Annegers JF, Lairson DR, Reynolds TF. Estimating the cost of epilepsy. Epilepsia 1999; 40 (Suppl 8): 8-13.

58. Annegers JF, Beghi E, Begley CE. Cost of epilepsy: contrast of methodologies in United States and European studies. Epilepsia 1999; 40 (Suppl 8): 14-8. 
59. Begley CE, Lairson DR, Reynolds TF, Coan S. Early treatment cost in epilepsy and how it varies with seizure type and frequency. Epilepsy Res. 2001; 47: 205-15.

60. Begley CE, Beghi E. The economic cost of epilepsy: a review of the literature. Epilepsia 2002; 43 (Suppl 4): 3-9.

61. Begley CE, Famulari M, Annegers JF et al. The cost of epilepsy in the United States: an estimate from population-based clinical and survey data. Epilepsia 2000; 41: 342-51.

62. Begley CE, Annegers JF, Lairson DR, Reynolds TF, Hauser WA. Cost of epilepsy in the United States: a model based on incidence and prognosis. Epilepsia 1994; 35: 1230-43.

63. Freeman JM. Less testing is needed in the emergency room after a first afebrile seizure. Pediatrics 2003; 111: 194-6.

64. Gordon KE, Dooley JM, Wood E, Brna P, Bethune P. Which characteristics of children with a febrile seizure are associated with subsequent physician visits? Pediatrics 2004; 114: 962-4.

65. Kurugol NZ, Tutuncuoglu S, Tekgul H. The family attitudes towards febrile convulsions. Indian J.Pediatr. 1995; 62: 69-75.

66. Crocetti M, Moghbeli N, Serwint J. Fever phobia revisited: have parental misconceptions about fever changed in 20 years? Pediatrics 2001; 107: 1241-6.

67. Benjamin PY. Psychological problems following recovery from acute life-threatening illness. Am.J.Orthopsychiatry 1978; 48: 284-90.

68. Perrin EC, West PD, Culley BS. Is my child normal yet? Correlates of vulnerability. Pediatrics 1989; 83: 355-63.

69. Balslev T. Parental reactions to a child's first febrile convulsion. A follow-up investigation. Acta Paediatr Scand. 1991; 80: 466-9.

70. Forsyth BW, Horwitz SM, Leventhal JM, Burger J, Leaf PJ. The child vulnerability scale: an instrument to measure parental perceptions of child vulnerability. J.Pediatr.Psychol. 1996; 21: 89-101.

71. Estroff DB, Yando R, Burke K, Snyder D. Perceptions of preschoolers' vulnerability by mothers who had delivered preterm. J.Pediatr.Psychol. 1994; 19: 709-21.

72. Allen EC, Manuel JC, Legault C, Naughton MJ, Pivor C, O'Shea TM. Perception of child vulnerability among mothers of former premature infants. Pediatrics 2004; 113: 267-73.

73. Levy JC. Vulnerable children: parents' perspectives and the use of medical care. Pediatrics 1980; 65: 956-63.

74. Thomasgard M, Metz WP. Differences in health care utilization between parents who perceive their child as vulnerable versus overprotective parents. Clin.Pediatr.(Phila) 1996; 35: 303-8. 